\title{
RESEARCH
}

Open Access

\section{Crosstalk between microglia and patient- derived glioblastoma cells inhibit invasion in a three-dimensional gelatin hydrogel model}

Jee-Wei Emily Chen ${ }^{1,2,3}$, Jan Lumibao ${ }^{2,4,5}$, Sarah Leary ${ }^{6}$, Jann N. Sarkaria ${ }^{7}$, Andrew J. Steelman ${ }^{8}$, H. Rex Gaskins $2,4,8,9$ and Brendan A. C. Harley ${ }^{1,2,3,9^{*}}$ (D)

\begin{abstract}
Background: Glioblastoma is the most common and deadly form of primary brain cancer, accounting for more than 13,000 new diagnoses annually in the USA alone. Microglia are the innate immune cells within the central nervous system, acting as a front-line defense against injuries and inflammation via a process that involves transformation from a quiescent to an activated phenotype. Crosstalk between GBM cells and microglia represents an important axis to consider in the development of tissue engineering platforms to examine pathophysiological processes underlying GBM progression and therapy.

Methods: This work used a brain-mimetic hydrogel system to study patient-derived glioblastoma specimens and their interactions with microglia. Here, glioblastoma cells were either cultured alone in 3D hydrogels or in coculture with microglia in a manner that allowed secretome-based signaling but prevented direct GBM-microglia contact. Patterns of GBM cell invasion were quantified using a three-dimensional spheroid assay. Secretome and transcriptome (via RNAseq) were used to profile the consequences of GBM-microglia interactions.

Results: Microglia displayed an activated phenotype as a result of GBM crosstalk. Three-dimensional migration patterns of patient-derived glioblastoma cells showed invasion was significantly decreased in response to microglia paracrine signaling. Potential molecular mechanisms underlying with this phenotype were identified from bioinformatic analysis of secretome and RNAseq data.

Conclusion: The data demonstrate a tissue engineered hydrogel platform can be used to investigate crosstalk between immune cells of the tumor microenvironment related to GBM progression. Such multi-dimensional models may provide valuable insight to inform therapeutic innovations to improve GBM treatment.
\end{abstract}

Keywords: Glioblastoma, Microglia, Invasion, Hydrogel

\footnotetext{
* Correspondence: bharley@illinois.edu

'Department of Chemical \& Biomolecular Engineering, University of Illinois at Urbana-Champaign, Urbana, IL 61801, USA

${ }^{2}$ Carl R. Woese Institute for Genomic Biology, University of Illinois at Urbana-Champaign, Urbana, IL 61801, USA

Full list of author information is available at the end of the article
}

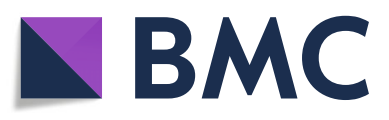

(๑) The Author(s). 2020 Open Access This article is licensed under a Creative Commons Attribution 4.0 International License, which permits use, sharing, adaptation, distribution and reproduction in any medium or format, as long as you give appropriate credit to the original author(s) and the source, provide a link to the Creative Commons licence, and indicate if changes were made. The images or other third party material in this article are included in the article's Creative Commons licence, unless indicated otherwise in a credit line to the material. If material is not included in the article's Creative Commons licence and your intended use is not permitted by statutory regulation or exceeds the permitted use, you will need to obtain permission directly from the copyright holder. To view a copy of this licence, visit http://creativecommons.org/licenses/by/4.0/. The Creative Commons Public Domain Dedication waiver (http://creativecommons.org/publicdomain/zero/1.0/) applies to the data made available in this article, unless otherwise stated in a credit line to the data. 


\section{Introduction}

Glioblastoma (GBM) is the most common and deadly form of central nervous system cancer [1, 2]. In the USA, it is estimated that more than 13,000 patients are diagnosed with GBM annually. Unlike many other cancers, GBM rarely metastasizes to a secondary organ, but instead diffusely infiltrates throughout the brain. The current standard of care for treating GBM consists of maximal surgical resection, radiotherapy, and concomitant and adjuvant chemotherapy with temozolomide $[1,3,4]$. Despite this aggressive treatment strategy, GBM tumors commonly recur with a median survival of less than 18 months, and fewer than $5 \%$ of patients surviving to 5 years [5-11]. A central focus for improving GBM therapy is developing new tools to understand pathophysiological processes driving GBM invasion of the brain. Improved therapy will likely require both an improved understanding of which cells within the heterogeneous cell population of GBM tumors invade surrounding tissues, and the extent to which cell-cell crosstalk within heterogeneous cell cohorts contribute to GBM invasion and mortality [12-18].

Microglia (MG) are resident immune cells of the CNS $[19,20]$. In healthy individuals, microglia constantly survey their surroundings and maintain tissue homeostasis by removing apoptotic cells and promoting neuronetwork generation [20-22]. Studies of the GBM tumor microenvironment have demonstrated that infiltrative and resident immune cells, such as microglia, may comprise up to a third of the solid tumor mass [20-22]. Morphologically, quiescent microglia typically exhibit a ramified (branching and elongated) shape. Upon stimulation in response to inflammation, disease, or tumor growth, microglia cell processes become hypertrophic and, in some cases, retract causing the cell to take on an ameboid appearance. While the number and phenotype of immune cells have been associated with patient prognosis [19, 23-27], detailed analysis of crosstalk between GBM cells and microglia are difficult to evaluate in vivo. Thus, there is a need for an experimental platform to rigorously investigate interactions between GBM cells and microglia, as well as to identify factors associated with microglia-GBM crosstalk that may alter GBM cell invasion and therapeutic response. Cancer tissue engineering platforms that integrate biomaterial mimics of the tumor microenvironment with primary cells and biomolecules are increasingly used to investigate pathophysiological processes difficult to examine in vivo [28, 29].

We previously developed a gelatin-based hydrogel model platform to investigate pathophysiological processes underlying GBM cell invasion and therapeutic response. Notably, we observed that biophysical (hyaluronan content and molecular weight) and metabolic (hypoxia) transitions in the GBM tumor microenvironment both significantly alter GBM invasion [30-32]. More recently, we adapted this system to profile cytokine-based crosstalk between cells within the GBM tumor microenvironment, identifying secreted factors generated by an artificial perivascular niche that can accelerate GBM cell invasion [33]. The objective of the present study was to adapt this established hydrogel platform and cytokine analysis protocols to examine the effects of microglia within the GBM tumor microenvironment on GBM gene expression and invasiveness using patient-derived GBM specimens that maintain patientspecific morphologic and molecular phenotypes [34, 35].

\section{Materials and methods \\ Cell culture \\ Human GBM cells}

Patient-derived GBM cells (PDCs) were obtained from Mayo Clinic (Rochester, Minnesota). All specimens used in this study (GBM12 and GBM39) were derived from tumors from different patients then maintained as patient-derived xenografts in nude mice [34, 35]. All patients consented to the use of their tumor tissue in support of this research, and the use of the patient tissues received prior institutional review board authorization. GBM12 exhibits overexpressed epidermal growth factor receptor $\left(E G F R^{O E}\right)$ and displays medium invasive potential in vivo. GBM39 possesses an EGFR variant III mutation $\left(E G F R^{v I I I}\right)$ and displays low invasive potential in vivo [34, 35]. GBM PDCs were established in Dulbecco's modified Eagle's medium (DMEM; Gibco, MD) supplemented with $10 \%$ fetal bovine serum (FBS; Atlanta Biologicals, Atlanta, GA) and $1 \%$ penicillin/streptomycin (Lonza, Basel, Switzerland) at $37{ }^{\circ} \mathrm{C}$ in a $5 \% \mathrm{CO}_{2}$ environment. PDCs were shipped by overnight courier and seeded into hydrogel cultures immediately upon arrival.

\section{Human microglia cell line}

HMC3 microglia cells (ATCC ${ }^{\bullet}$ CRL-3304, ATCC) were cultured in DMEM supplemented with $10 \%$ FBS and $1 \%$ $\mathrm{P} / \mathrm{S}$. Cells were incubated at $37{ }^{\circ} \mathrm{C}$ in $5 \% \mathrm{CO}_{2}$ and passaged upon reaching confluence.

\section{Primary mouse microglial cultures}

All animal care protocols were in accordance with $\mathrm{NIH}$ Guidelines for Care and Use of Laboratory Animals and were approved by the University of Illinois Laboratory Animal Care and Use Committee. Both male and female C57BL/6J mice (The Jackson Laboratory, Bar Harbor, $\mathrm{ME)}$ were used to obtain primary microglial cultures as described previously [36]. In brief, neonatal (P1-2) mouse pups were decapitated with scissors, the brains were extracted, and the meninges removed under a dissection microscope (Leica, Wetzlar, Germany). Brain tissues were pooled from entire litters, dissociated in Accutase (Thermo Fisher Scientific, Waltham, MA) followed by washing and removal of excess debris. Cells 
were seeded onto poly-d-lysine-coated (Sigma-Aldrich, St. Louis, MO) T75-flasks. After approximately eight days of culture, the flasks were shaken at $37^{\circ} \mathrm{C}$ for $1 \mathrm{~h}$ at $170 \mathrm{rpm}$ in an orbital shaker (Max Q 4000; Thermo Fisher Scientific). The supernatant containing microglia was then collected [36].

\section{Methacrylated gelatin hydrogel fabrication and characterization \\ Synthesis and fabrication}

Methacrylamide-functionalized gelatin (GelMA) macromers and GelMA hydrogels were synthesized and prepared as previously described [30, 37]. GelMA degree of functionalization was determined by ${ }^{1} \mathrm{H}$ NMR spectroscopy ( $50 \%$ degree of functionalization).

\section{Hydrogel characterization}

The compressive modulus of GelMA hydrogels was measured using an Instron 5943 mechanical tester [31]. Hydrogels were tested under unconfined compression at the rate of $0.1 \mathrm{~mm} / \mathrm{min}$, with their Young's modulus obtained from the linear region of the stress-strain curve (2.5-17.5\% strain).

\section{Cell number determination}

Cell-containing hydrogels were made similarly but with addition of cell suspensions (5000 cells per $25 \mu \mathrm{L}$ hydrogel) or cell spheroids (5000 cells per spheroid per $25 \mu \mathrm{L}$ hydrogel) to the pre-polymer solution prior to being placed into Teflon molds $(0.2 \mathrm{~mm}$ thick, $5 \mathrm{~mm}$ radius $)$ and then photopolymerized.

Hydrogel identification: To distinguish hydrogels containing PDCs versus microglia, all hydrogel specimens containing microglia were cut into half-disks before being placed into culture while GBM seeded hydrogels were maintained as full disks.

\section{Protein Isolation and Western Blotting}

Proteins from HMC3 microglia cultured in hydrogels (cell suspensions) were isolated using protocols described previously [30-32]. Western blots $(2 \mu \mathrm{g}$ per lane) were probed with primary antibodies specific for CD68 [38] (ab213363, 1/500 in blocking buffer; Abcam, Cambridge, UK) or $\beta$-actin (4967S, 1/1000 in blocking buffer; Cell Signaling Technology, Danvers, MA), stained via secondary antibody (7074S, 1/2500 in TBST; Cell Signaling Technology), then imaged via an Image Quant LAS 4010 chemiluminescence imager (GE Healthcare, Chicago, IL). Band intensities were quantified using Image and normalized to $\beta$-actin intensities.

\section{Immunofluorescence staining and imaging}

Image-i $\mathrm{T}^{\mathrm{m}}$ Fixative Solution (Invitrogen, Carlsbad, CA) was used to fix HMC3 microglia seeded hydrogels (cell suspensions). Cells were permeabilized with $0.1 \%$ Triton X-100 (Sigma-Aldrich) in PBS and stained with Alexa Fluor $^{\text {rm }} 488$ Phalloidin (Invitrogen) for F-actin and Hoechst 33342 (Invitrogen) for nuclei following the manufacturer's protocol. Stained samples were imaged using a Zeiss LSM 700 confocal microscope.

\section{RNA extraction and quality analysis}

Total RNA of GBM cell-seeded hydrogels (cell suspensions) was extracted using an RNeasy Plant Mini Kit (Qiagen, Hilden, Germany) with an additional step using an RNase-free DNase set (Qiagen) for DNase digestion. RNA integrity number (RIN) was determined using an Agilent 2100 bioanalyzer with all samples exhibiting a RIN $>8$.

\section{RNAseq analysis}

Libraries for RNA sequencing were prepared using the TruSeq Stranded mRNAseq Sample Prep Kit (Illumina, San Diego, CA). The libraries were quantitated by qPCR and sequenced on one lane for 101 cycles from one end of the fragments on a NovaSeq 6000 (Illumina) using a NovaSeq SP reagent kit and yielded 400 to 500 million single reads per lane. Library quality check was done using FastQC (version 0.11.8). Salmon version 0.13.1 was used to quasi-map reads to the transcriptome and quantify the abundance of each transcript. Filtering was set with the threshold of 0.5 counts per million and resulted in 15,901 genes to be analyzed for differential expression that contained $>99.5 \%$ of the reads. After filtering, trimmed mean of $\mathrm{M}$ values (TMM) normalization in the edgeR package was performed and log2-based count per million values $(\log C P M)$ were calculated [3941]. Differential gene expression analysis was performed using the limma-trend method. Multiple testing correction was done using the false discovery rate (FDR) method [42-44]. Functional annotation was performed, gene ontology (GO) KEGG pathways were identified using an overrepresentation test [45]. The 50 genes with the highest fold-changes were subsequently examined in Cytoscape using the application iRegulon to predict transcriptional regulators [46, 47]. Putative transcription factors or motifs with a normalized enrichment score larger than three $(\mathrm{NES}>3)$ is considered to be potential regulators.

\section{Spheroid invasion assay}

We have previously reported a robust, three-dimensional assay to quantify GBM cell invasion in three-dimensional hydrogels [48-50]; GBM cell invasion is reported as total radial invasion distance or as a normalized value such as the average radius fold change (mean radius of the invasion front of GBM cells from a GBM spheroid versus the starting radius of the spheroid). Briefly, GBM12 PDCs 
were counted and resuspended into 5000 cells $/ 200 \mu \mathrm{L}$ media per well and distributed to Corning spheroid microplates. Plates were centrifuged for $100 \times g$ for $1 \mathrm{~min}$ to assist spheroid formation then placed into incubator (37 ${ }^{\circ} \mathrm{C}, 5 \% \mathrm{CO}_{2}$ ) for $24 \mathrm{~h}$. Plates were then incubated for additional $24 \mathrm{~h}$ with horizontal shaking at $60 \mathrm{rpm}$. Spheroids were then transferred and mixed with pre-polymerized GelMA solution and photopolymerized into hydrogels. Spheroid images were acquired using a Leica DMI 400B florescence microscope (Leica, Germany) at days 0 (immediately upon seeding), 1, 3, 5, and 7. Invasion was then quantified via Image and invasion distance reported as fold change of their average radius compared to day 0 as described previously [30, 31].

\section{Quantification of cell number}

GBM12 cell proliferation in cell suspension hydrogels was determined using a commercial Vybrant ${ }^{\circ}$ MTT Cell Proliferation Assay Kit (Invitrogen) adapted from the manufacturer's protocol as described previously [30, 32, 51].

\section{Secretome profiling}

Cell culture media was collected from the following group: GBM-MG co-cultures (co-culture), GBM cells alone (GBM single), or MG cells alone (MG single). The media were spun down $(300 \times g, 10 \mathrm{~min})$ to remove any debris. As an additional control, we created a 1:1 mixture of GBM single and MG single media (Mix) that would not account for any GBM-MG crosstalk mediated shifts in secretome. The secretome for each specimen was profiled using a Proteome Profiler ${ }^{\mathrm{TM}}$ Human Angiogenesis Array Kit (Ary007, R\&D Systems, Minneapolis, $\mathrm{MN}$ ) following the manufacturer's protocol. Blots were imaged using an Image Quant LAS 4010 chemiluminescence imager (GE Healthcare). Dot intensities were quantified with the ImageJ macros toolset Protein Array Analyzer (Table S1). Data was first normalized by dividing the pixel intensity for each blot by the average positive control pixel intensity (on each membrane). We calculated intensity fold change between co-culture and mix groups, identifying factors that displayed a larger than 1.5 -fold change; targets showing $>0.75$-fold change relative to positive reference spot intensities was plotted.

\section{Statistical analysis}

Statistical analysis for Western blot was performed via $t$ test. Analysis of MTT was performed via one-way ANOVA followed by Tukey's HSD post hoc test. Analyses of invasion were performed via two-way ANOVA followed by Tukey's HSD post hoc test. Significance level was set at $p<0.05$ unless stated otherwise $(p<0.01$ and $p<0.0001)$. A minimum of $n=3$ samples was used for all analyses and specified in each result section. Error bars are plotted as the standard error.

\section{Results \\ Co-culture system assembly and mechanical testing of GelMA hydrogel}

We have previously developed a family of gelatin hydrogels to investigate pathophysiological processes underlying glioblastoma invasion and progression. Extensive biophysical performance data has previously been reported including network architecture and mechanical performance $[52,53]$, water and small-molecule diffusivity [54-56], and the capacity to support growth and phenotypic studies of primary glioblastoma cells and cells from the neurovascular unit $[57,58]$. For this project, GBM and MG cells were maintained in three-dimensional culture in a $4 \mathrm{wt} \%$ methacrylamide-functionalized gelatin (GelMA) that exhibited a physiologically relevant Young's modulus (1.04 $\pm 0.10 \mathrm{kPa} ; n=14$; Fig. 1a) [59, 60]. For this study, individual ( $G B M$ single, $M G$ single) cultures were generated as either GBM

or MG-seeded hydrogel disks in separate culture wells. Alternatively, GBM and MG seeded hydrogel disks were cultured together in the same well (co-culture), allowing exchange of secreted factors between hydrogel disks but not allowing direct cell-cell contact (Fig. 1b).

\section{Microglia become activated when co-cultured with GBM cells}

Microglia displayed significant morphological changes as a result of GBM-MG crosstalk (Fig. 2). HMC3 microglia cultured individually in GelMA hydrogels ( $M G$ single) exhibited the characteristic elongated shape of quiescent MG. However, in response to co-culture with GBM12seeded hydrogels (GBM-MG co-culture), MG adopted a rounded ameboid shape associated with activation (Fig. 2a). To confirm this shift in activation status, changes in the expression of the lysosomal protein CD68 were examined via Western blot $(n=3)$. While CD68 is normally expressed at low levels in quiescent microglia, CD68 expression was increased in microglia co-cultured with GBM cells (Fig. 2b, c). Raw image files of Western blot analyses are provided in Figures S1 and S2.

\section{Soluble factors produced by microglia altered GBM transcriptomic profiles}

RNAseq analysis was used to examine global shifts in the transcriptomic profile of GBM12 specimens as a result of MG crosstalk. Two RNAseq datasets were compared: (1) a co-culture specimen containing RNA isolated from the GBM-seeded hydrogels kept in physically separated co-culture with HMC3 MG-seeded hydrogels; and (2) a GBM single culture specimen containing RNA isolated from GBM-seeded hydrogels cultured independently ( $n=3$ for each group). This comparison allowed investigation of global shifts in GBM gene expression profiles only due to GBM-MG crosstalk (Fig. 3). 

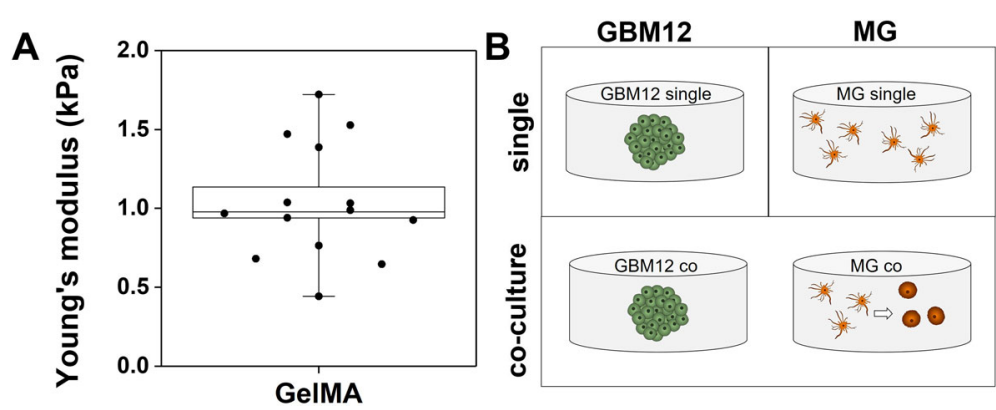

Fig. 1 GelMA hydrogel biophysical parameters and experimental schematic. a Mechanical testing results of GelMA hydrogel confirmed its physiologically relevant Young's modulus $(1.04 \pm 0.10 \mathrm{kPa} n=14)$. b Schematic representation of the culture system, that either has a single type of cell-seeded hydrogel disk per well (GBM single, MG single) or contains two distinct hydrogel disks (GBM-MG co-culture). GBM-MG co-culture allows soluble signaling without physical GBM-MG contact

Differential gene expression (DE) analysis was performed using an FDR-adjusted $p$ value set to 0.05 . In total, there were $3409 \mathrm{DE}$ genes, of which 1563 were upregulated and 1846 were downregulated as a result of co-culturing GBM cells with microglia. Gene ontology (GO) analysis for biological process ontology showed upregulated genes were associated with proliferation and RNA/DNA replication and proliferation, while downregulated genes were associated with motility, adhesion, and invasion (Supplementary Table S1; Fig. 3b).

KEGG pathway analysis was used to identify the top 20 up- and downregulated pathways (Table S2; Fig. 3c). GBM-MG co-culture downregulated multiple immune response-related pathways in GBM cells including nucleotide-binding and oligomerization domain $(N O D)$ like receptors (NLRs), tumor necrosis factor (TNF) signaling, nuclear factor kappa-beta $(N F-\kappa B)$ signaling, tolllike receptor signaling (TLRs), and mitogen-activated protein kinase (MAPK) signaling. GBM-MG co-culture decreased focal adhesion pathway activation. Upregulated KEGG pathways included those involved in cell proliferation and survival included thyroid hormone signaling, Janus kinase-signal transducer and activator of transcription pathway (JAK-STAT) signaling, central carbon metabolism, forkhead box transcription factors $(F O X O)$ signaling, and adenosine monophosphate-activated protein kinase $(A M P K)$ signaling. Intriguingly, EGFR tyrosine kinase inhibitor resistance was also increased, indicating that the co-culture might also alter the therapeutic response to classes of drugs targeting receptor tyrosine kinase inhibitors. iRegulon analysis of upregulated genes showed high normalized enrichment scores for SUZ12 (NES $=7.021$ ), RCOR1 (NES = 5.834), and REST (NES = 5.475). iRegulon analysis also showed high normalized enrichment scores for downregulated genes STAT1/2/3 (NES $=15.831 /$ $13.455 / 3.002)$ and $I R F 1 / 5 / 8$ (NES $=8.029,8.440,13.813)$. Together, these analyses indicate that co-culture with microglia induces significant shifts in GBM transcriptome linked to increased proliferative behavior and decreased invasive potential.

\section{Microglial soluble factors inhibit GBM invasion}

GBM proliferation and invasion was subsequently examined as a function of MG co-culture. The proliferative activity of GBM12 cells, reported as a fold change increase in MTT activity (MTT of GBM cells at day 3 vs. MTT of the same cultures at day 0), increased significantly in response to GBM-MG co-culture (Fig. 4a). MG co-culture strongly inhibited GBM12 invasion over the course of a seven-day spheroid-based invasion assay, with effects observed as early as after $24 \mathrm{~h}$ (Fig. 4b, c). A consistent inhibitory effect of MG co-culture on GBM invasion was observed as well for a different source of microglia (primary neonatal microglia, nMG) and a different patient-derived GBM cell population (GBM39: $\left.E G F R^{V I I I}\right)$. GBM39 show reduced invasive potential in vivo compared to GBM12, but nonetheless GBM39 invasion was again significantly inhibited in the multidimensional hydrogel model in response to nMG coculture, with effects observed as early as day 3 (Fig. 5).

\section{Profiling MG-GBM secretome using cytokine array}

A secretome screen was performed to compare cell culture media from GBM-MG co-culture versus GBM or MG monocultures (GBM single, $M G$ single) and a Mix media (1:1 mixture of $G B M$ single and $M G$ single medias; Fig. 6; raw data are available in Table S3). Eight factors exhibited a $>1.5$ fold change in co-culture vs. single cultures: chemokine ligand 2 and 3 (CCL2, CCL3); insulin-like growth factor binding protein 3 (IGFBP-3); angiogenin (ANG); heparin-binding epidermal growth factor-like growth factor (HB-EGF); dipeptidyl peptidase-4 (DPP4); Serpin F1; and coagulation factor III (F3). Six factors were expressed at levels greater than 0.75 of the positive reference intensity value within each secretome array (Fig. 6c). Of these, CCL2 showed the largest activation 

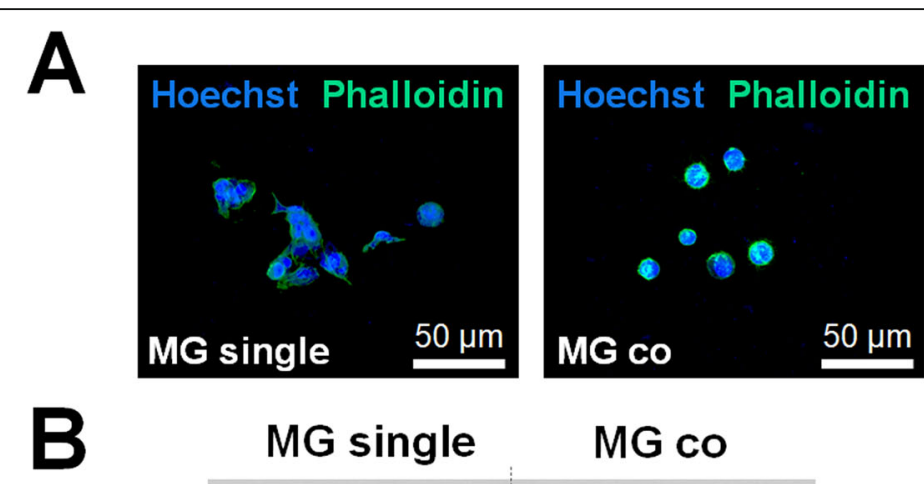

MG single
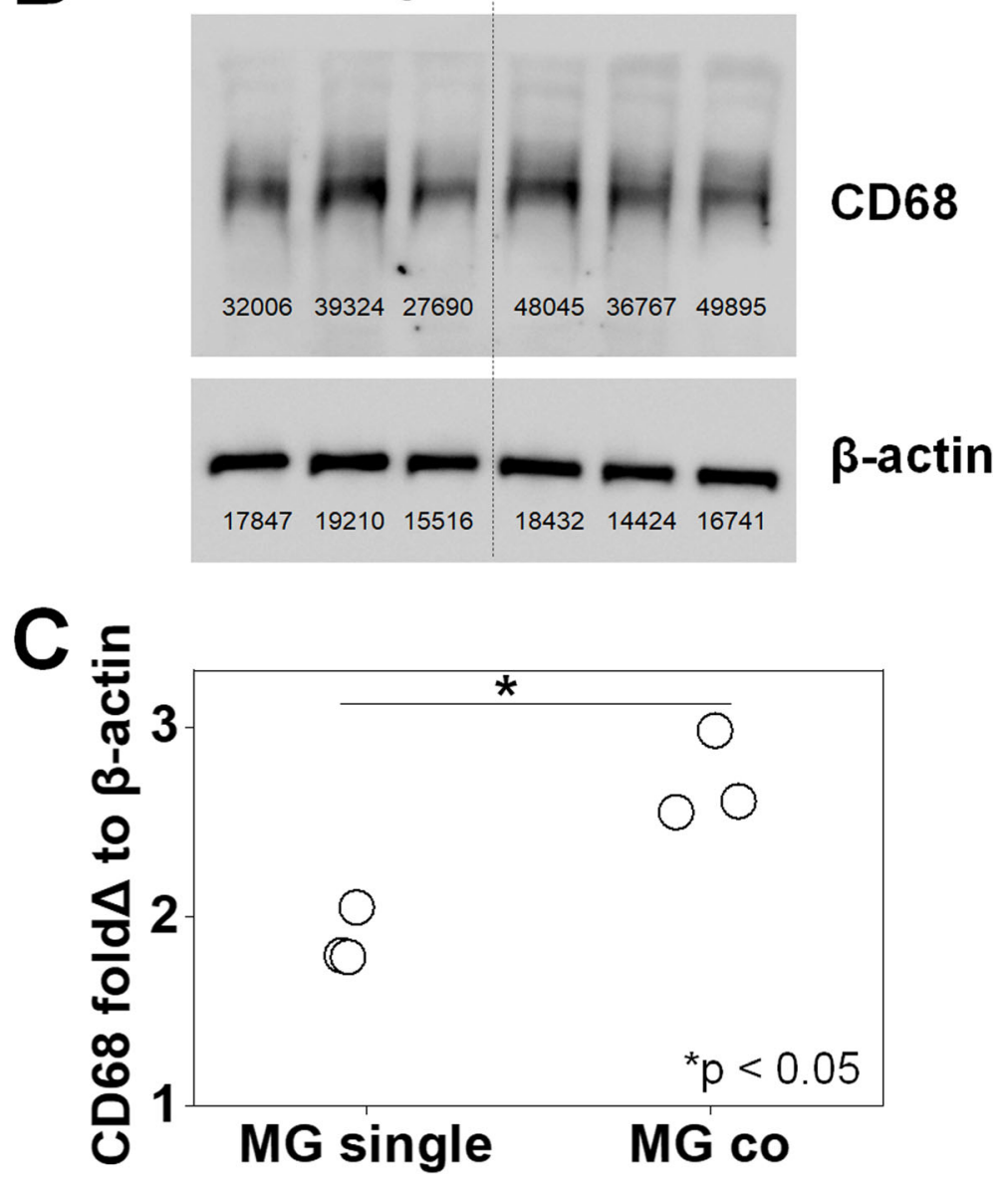

Fig. 2 Verification of microglia activation via morphological and protein expression analyses. a Immunofluorescence staining of Alexa488Phalloidin ${ }^{+}$actin (green) showing HMC3 microglia morphology in MG single (elongated quiescent) or GBM-MG co-culture (ameboid, activated). Also, Hoechst $33342^{+}$nuclei stained blue. $\mathbf{b}$ Western blot staining CD68 and $\beta$-actin in triplicate. MG single on the left and MG coculture on the right. c CD68 protein expression levels $(n=3)$ in microglia increased as a result of GBM co-culture. ${ }^{*} p<0.05$

(> 2-fold change) for GBM-MG co-culture versus the Mix media control. Granulocyte-macrophage colonystimulating factor (GM-CSF, or CSF2) and pentraxinrelated protein (PTX3) were both highly expressed in cultures containing MG (MG-single, Mix, co-culture) media but lowly expressed in GBM-single hydrogels. Serpin E1, tissue inhibitor of metalloproteinase-1 (TIMP1 ), and vascular endothelial growth factor (VEGF) were expressed across all culture conditions.

\section{Discussion}

Cellular crosstalk within the tumor microenvironment provides a powerful avenue of interaction that may significantly shape disease progression. Tools to interrogate cellular crosstalk offer an opportunity to identify novel therapeutic compounds to improve treatment of glioblastoma. This work demonstrates the use of a tissue engineering platform to investigate the role of crosstalk between patient-derived GBM specimens and microglia 
A

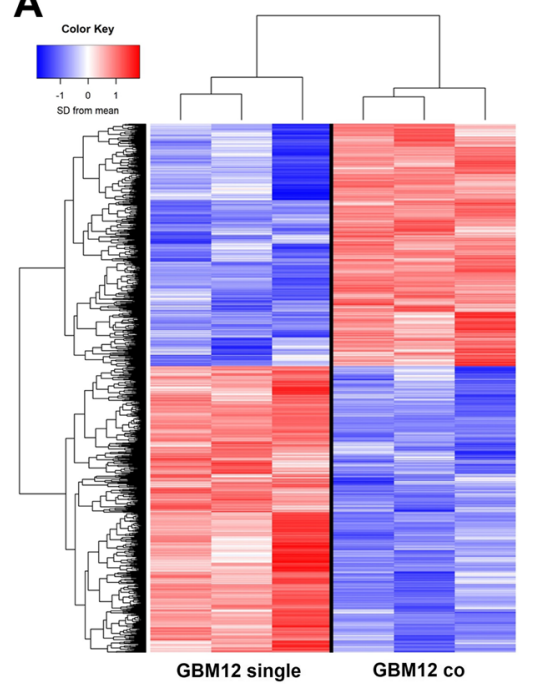

B

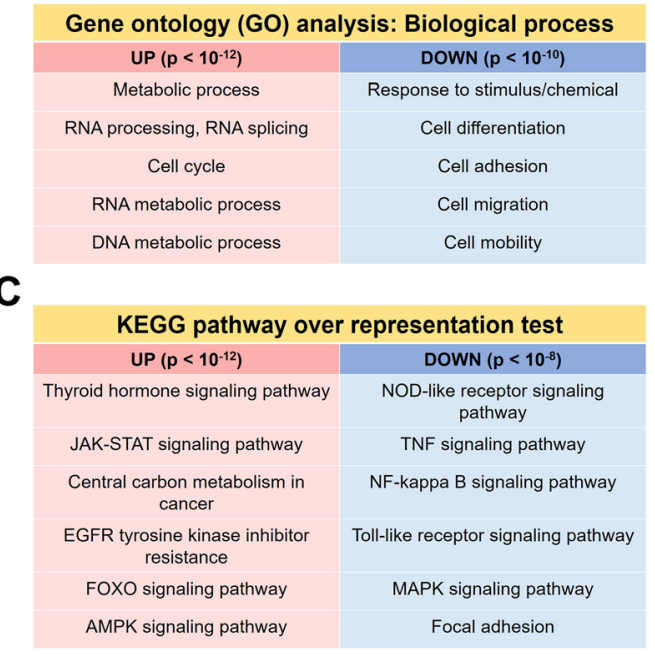

D

\begin{tabular}{|c|c|c|c|c|c|c|c|}
\hline \multicolumn{8}{|c|}{ iRegulon Analysis } \\
\hline & Transcription Factor & NES & \#Targets & & Transcription Factor & NES & \#Targets \\
\hline \multirow{6}{*}{ Up } & SUZ12 & & 11 & \multirow{6}{*}{ Down } & STAT1 & 15.837 & 34 \\
\hline & & 7.021 & 11 & & IRF8 & 13.813 & 36 \\
\hline & RCOR1 & 5834 & 5 & & STAT2 & 13.455 & 19 \\
\hline & & 5.034 & J & & IRF5 & 8.444 & 29 \\
\hline & \multirow{2}{*}{ REST } & \multirow{2}{*}{5.475} & \multirow{2}{*}{30} & & IRF1 & 8.029 & 33 \\
\hline & & & & & STAT3 & 3.002 & 14 \\
\hline
\end{tabular}

Fig. 3 Soluble signals from microglia induced shifts in GBM12 cell transcriptome. a RNAseq and differential gene expression analysis ( $p<0.05$ ) identified 1563 upregulated genes and 1846 downregulated genes in GBM12 co compared to GBM12 single. Selected (b) gene ontology (GO) and (c) KEGG pathway terms suggest GBM-MG interactions underlie upregulated expression of genes involved in GBM proliferation and genes with diminished expression associated with GBM invasion. ( $n=3$ for GBM12 single and GBM12 co) (d) Significant putative genes from the top 50 genes with normalized enrichment score $>3$ were identified via iRegulon

on shifts in the phenotypic, proteomic, and transcriptomic signatures of GBM. GBM-MG crosstalk is bidirectional and induces microglia activation along with shifts in GBM cell activity consistent with the go-or-grow phenomenon [61]. This work extends technical capabilities beyond more traditional Transwell membrane or mixed culture methods for examining cell-cell crosstalk. Importantly, this effort provides a platform for analysis of individual cell populations, each maintained within discrete multi-dimensional models of the tumor microenvironment, while maintaining the ability to examine the nature and role of cell-cell crosstalk during mixed culture on cell activity.

While microglia display a quiescent phenotype in single culture, hallmarks of microglial activation were observed via both morphological changes and increased CD68 expression as a result of GBM-MG co-culture. These results are consistent with hallmarks of microglial activation seen in cases of disease and histopathological analysis of GBM tumors [24, 62]. The nature of this tissue engineering platform allows significant post-culture analysis of GBM cell activity at functional (invasion, proliferation), transcriptomic (RNAseq), and secretomic levels. We recently reported the use of gelatin hydrogels to profile to role of localized hypoxia on activation of cells associated with the neurovascular unit [58]. Indeed, while a single hydrogel formulation was used for all microglial culture in this study, significant opportunities exist to use multi-dimensional hydrogels culture to refine our understanding of the role of the matrix microenvironment on microglia activation itself.

While advanced sequencing techniques such as RNA sequencing offer the opportunity to define the transcriptomic signature of cells to aid treatment planning and outcome prediction $[40,43,44,63]$, the design of the hydrogel culture system reported here enabled analysis of shifts in the transcriptome of individual cell populations as a result of heterotypic cell (GBM, MG) crosstalk. GO analyses revealed GBM-MG co-culture upregulated genes in a patient-derived GBM specimen associated with cell cycle, RNA/DNA division and metabolic activity. However, genes involved in cell adhesion/migration showed significant downregulation as a result of GBMMG co-culture. These findings indicate tradeoffs in GBM proliferation versus invasion due to MG crosstalk consistent with the go-or-grow dichotomy of GBM cells $[32,61,64,65]$. Significant decreases were observed in expression of genes associated with $N L R, T N F, N F-\kappa B$, 


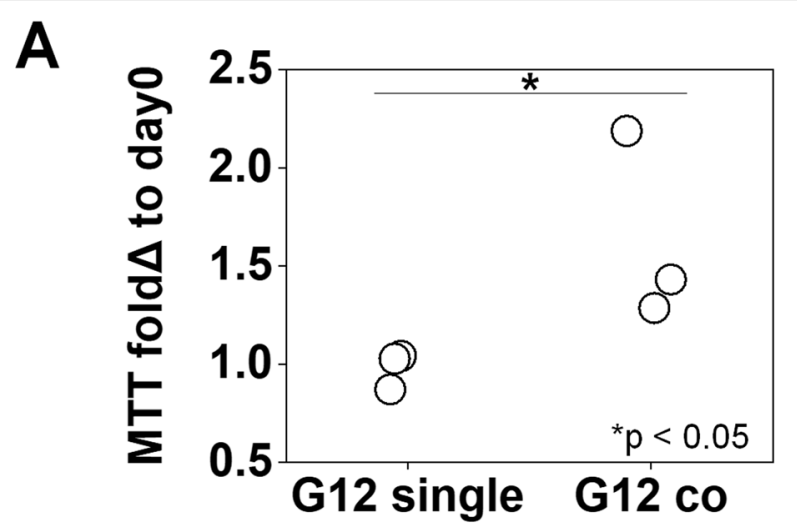

B

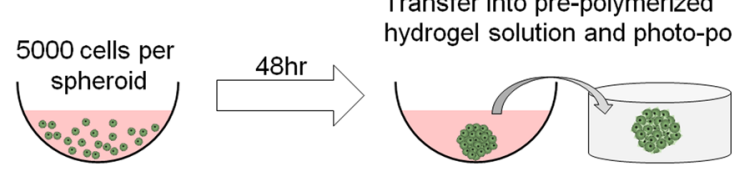

Ultra-Low Attachment Spheroid Microplate
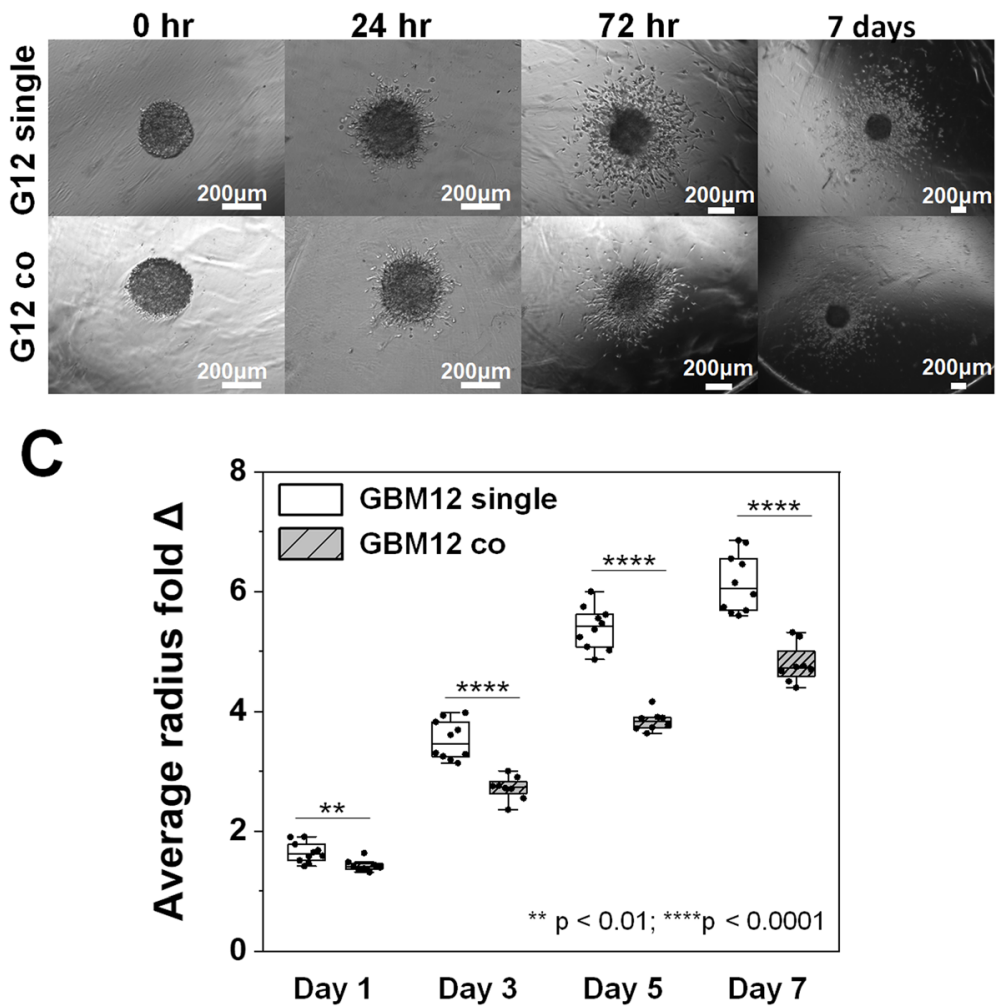

Fig. 4 Soluble factors from microglia increase GBM proliferation but significantly inhibit GBM12 invasion. a Significant increase in MTT fold change at day 3 in GBM12 cells co-cultured with MG compared to GBM12 single cultures (both $n=3$ ). b Representative images of spheroidbased invasion assay for GBM12 single cultures and GBM12-microglia co-cultures. Scale: $200 \mu$ m. c Quantification of GBM cell invasion in the presence or absence of soluble signals from microglia, with results reported as the mean radius of the invasion front of GBM cells versus the starting radius of the spheroid. GBM12 cells exhibited significantly decreased invasion $(n=8)$ in response to co-culture with HMC3 microglia (vs. GBM12 alone; $n=10) .{ }^{*} p<0.05,{ }^{* *} p<0.01,{ }^{* * *} p<0.0001$

$M A P K$, and TLR pathways in GBM specimens in response to MG co-culture. NLR and TLR signaling pathways are involved in pathophysiological responses to inflammation and tumor progression [66-68]. Of these, the $N F-\kappa B$ signaling pathway is known to be sensitive to TNF signaling [69-71] which plays a major role in 


\section{A neonatal pups

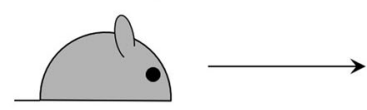 \\ primary neonatal microglia}
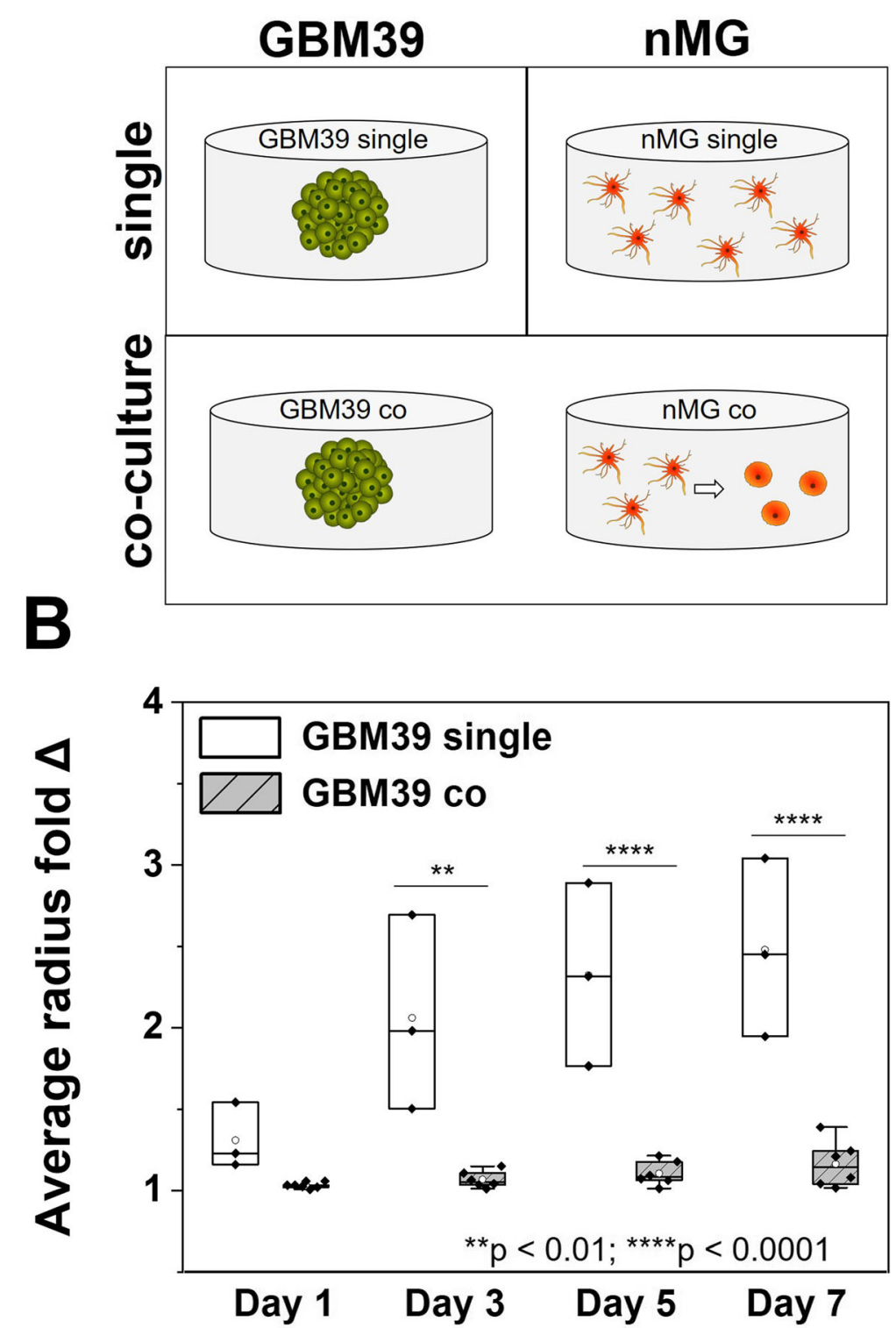

Fig. 5 Primary neonatal microglia strongly inhibit GBM invasion. a Primary neonatal microglia cells (nMG) were obtained from neonatal mouse pups. nMG and GBM39 seeded hydrogel disks were then either cultured alone (single) or together (co) in the same well of a 24-well plate. $\mathbf{b}$ GBM39 invasion was significantly decreased due to co-culture with nMG $(n=6)$ compared to GBM39 alone $(n=3) .{ }^{* *} p<0.01,{ }^{* * * *} p<0.0001$

immune activation [72, 73], breast cancer invasion [74], and driving TLR and MAPK signaling involved in cell migration and tumor invasion. These pathways contribute to heightened immune responsiveness and are involved in angiogenesis and cell migration $[66,67,69-71]$, suggesting GBM-MG interactions may inhibit GBM invasiveness.
KEGG analysis also showed strong upregulation in $T H$ and STAT3 signaling, indicating that secreted factors from microglia may promote GBM proliferation, reduce apoptosis, and enhance chemotherapeutic resistance [75-77]. Recently, our group showed STAT3 is strongly activated in GBM, and inhibiting STAT3 can reduce 

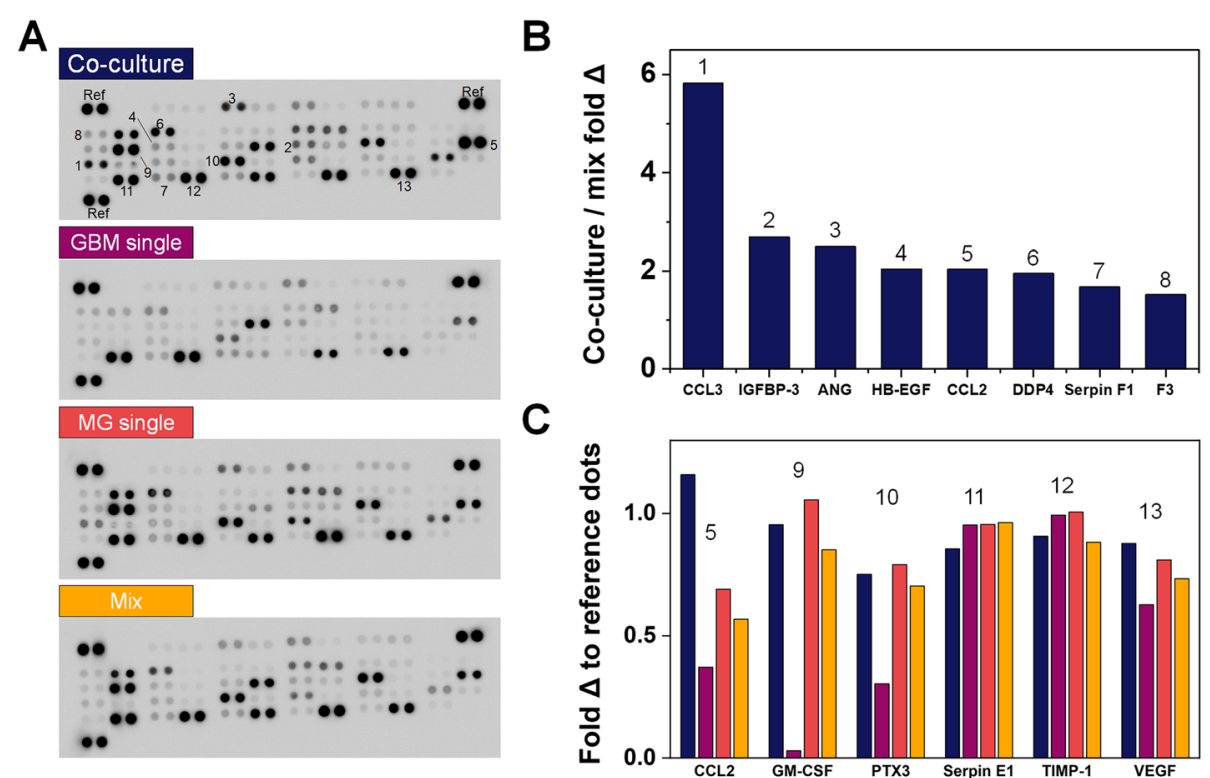

Fig. 6 Profiling GBM-MG (GBM12-HMC3) secretome linked to decreased GBM cell invasion. a Proteome Profiler ${ }^{\mathrm{TM}}$ Array analysis of secretome profiles from conditioned media of 4 distinct culture conditions: GBM-MG co-culture; GBM single; MG single; 1:1 Mix of GBM single; and MG single. $\mathbf{b}$ Eight factors that displayed $>1.5$ fold change in GBM-MG co-culture versus Mix media groups. c Six factors (from GBM-MG co-culture) that displayed greater than 0.75 -fold change versus the positive reference dots. Numbers (1-13) correspond to positions labeled on blots in a. Raw data are available in Table S3

GBM cell proliferation [52, 78]. More, GBM-MG co-culture upregulated FOXO signaling, which has been linked to therapeutic resistance due to its contribution to DNA repair as well as mediation of oxidative stress. iRegulon analysis showed GBM-MG crosstalk increased enrichment for SUZ12, previously shown to be increased in high grade astrocytoma and involved in pathways that regulate glioma proliferation and metastasis [79, 80]. iRegulon analysis also showed GBM-MG crosstalk increased REST and RCOR1, known to regulate the oncogenic properties of GBM stem cells [81] that associate with therapeutic resistance and recurrence $[82,83]$. The $I R F$ family has been shown to be significant tumor suppressors, inhibit tumor proliferation and loss of IRF genes may contribute to tumor metastasis and invasion [84, 85]. Together, analysis of transcriptomic data support the functional responses of increased proliferation but decreased invasion for GBM cells as a result of GBM-MG interactions [32, 65, 86-88]. Inclusion of RNAseq analyses to examine the role of microglia-GBM crosstalk provides a valuable dataset to motivate ongoing efforts. Indeed, while this study highlighted the importance of examining GBM-microglia interactions via RNAseq methods, ongoing efforts are using this approach to consider the role of microglia signaling on GBM subtractions such as glioblastoma stem cells (GSCs) as well as examining the behavior of GSCs within a larger cohort of GBM cells.
The hydrogel platform was subsequently used to experimentally interrogate the influence of GBM-MG crosstalk on GBM proliferative and invasive phenotypes in patientderived GBM12 cells. GBM12 cells exhibited significantly increased proliferation and significantly inhibited invasion in response to MG co-culture. Strikingly, MG-induced inhibition of GBM12 invasion was observed for multiple combinations of patient-derived GBM specimens and microglia: $E G F R^{O E}$ GBM12 cells co-cultured with HMC3 microglia and $E G F R^{\nu I I I}$ GBM39 cells co-cultured with primary mouse neonatal microglia.

Analysis of the combined GBM-MG secretome revealed multiple targets driving the observed shifts in functional and transcriptomic activity. CCL2 and CCL3 are associated with monocyte and macrophage recruitment [89-91] and may act as chemoattractant [89]. Of these, further study of the role of CCL2 in GBM invasion may be particularly warranted, as expression levels were not only significantly increased in GBM-MG $\mathrm{co}^{-}$ culture (vs. GBM-single or MG-single cultures) but also compared to the Mix control, consistent with synergistic activation of CCL2 secretion due to GBM-MG crosstalk. IGFBP-3, known to regulate cell proliferation, was also increased in GBM-MG crosstalk, though its role in cancer progression remains to be fully understood [92-94]. DPP4 (plasma membrane protein that contributes to immune and metabolic regulation [95, 96]) and HB-EGF (cell metabolic activity and tumor suppression in other 
cancers [95-97]) were also strongly upregulated in GBM-MG co-culture, as was ANG, well-known for its role in angiogenesis and cell proliferation [98, 99], and Serpin F1, known as for its role in suppression of tumor growth and prostate cancer metastasis [100-103]. Previous study by Shinozaki et al. [104] also indicated that cytokines produced by microglia could potentially drive astrocytes towards a neuroprotective phenotype upon brain injuries. While results here provide critical data regarding highly expressed factors within the combined MG-GBM secretome, ongoing opportunities exist to consider a wider range of secreted factors, consider the role of alternative signaling pathways such as extracellular vesicles in crosstalk, and to use machine learning algorithms to identify critical subsets of factors most highly associated with GBM cell response. Notably, we recently reported an iterative partial least squares regression machine learning methods to identify [105] secretome signals generated by niche-associated cells that enhance quiescence of hematopoietic stem cells in hydrogel culture. So, while further efforts are needed to more fully investigate the potential mediators of GBM invasion that arise from GBM-MG crosstalk, we present a robust platform to pursue such investigations here.

The immune system and immune cells and their relationship with cancer have been a hot topic in recent years. Tumor-associated macrophages/microglia, or GBM-associated macrophages/microglia here, has drawn a large amount or research efforts [19-21]. While some studies showed that the infiltrated microglia facilitates the tumor growth and targeting those infiltrated immunes cells could be a promising therapeutic approach [19-21, 106], the exact role of them remains controversial [107]. In the study, the combination of increased proliferation but decreased invasion aligns with the goor-grow hypothesis [64], but more importantly demonstrates that crosstalk between MG and GBM cells in the tumor microenvironment may have powerful effects on GBM activities tied directly to tumor progression and patient survival.

Finally, we note the value and limits of a tissue engineering approach described herein. Glioblastoma tumors contain a heterogeneous mix of cells, including a subpopulation of tumor initiating cells (GBM stem cells, GSCs) [108-110], critical for invasion, recurrence, and mortality [109, 111-117]. Tumors contain a mix of fibrillar matrix (e.g., collagens, laminins) and hyaluronic acid (HA), complex perivascular niches, regions of hypoxia [118], and multiple immune-associated cells including microglia and macrophages. Here, we report a multidimensional hydrogel platform to examine pathophysiological processes linked to GBM progression and mortality using patient-derived GBM specimens in response to microglia. We have also recently described hydrogel- based platforms to investigate the role of angiocrine signaling from engineered perivascular cultures on GBM cell invasion and resistance to the frontline chemotherapy temozolomide [57]. We also reported adaptations to the hydrogel environment via localized formation of hypoxic zone to support culture of a broader diversity of cells from the neurovascular unit [58]. While we acknowledge understanding the role of the coordinated activity of tumor-associated macrophages and microglia on the activity of GBM cell cohorts (or on specific cells from the GBM microenvironment such as GSCs) are essential, this manuscript provides a conceptual framework for pursuing such studies while also providing critical information regarding the role of reciprocal GBMmicroglia signaling on GBM invasion.

\section{Conclusion}

This study describes a tissue engineering platform to examine the role of GBM-microglia crosstalk on processes associated with GBM progression. It also shows the ability to use bioinformatic tools to identify transcriptomic shifts underlying these responses. We show dynamic, two-way interactions between patient-derived GBM cells and microglia via paracrine signaling influence both microglia and GBM cell phenotype. Microglia in the presence of patient-derived GBM cells showed morphological shifts associated with activation. Microglia co-culture significantly inhibited GBM invasion but enhanced proliferation that could be captured via threedimensional spheroid invasion assays and transcriptomic analyses. Future efforts will seek to understand the contribution of GBM-microglia crosstalk on tumor resistance to therapeutics, to reveal candidate signaling axes for rational combinatorial targeting.

\section{Supplementary information}

The online version contains supplementary material available at https://doi. org/10.1186/s12974-020-02026-6.

\footnotetext{
Additional file 1: Figure S1. Raw images for $\beta$-actin Western blot samples (left three: MG single; right three: MG co). Figure S2. Raw images for CD68 Western blot samples (left three: MG single; right three: MG CO) Table S1. Selected gene ontology (GO) biological process terms that showed significant differences in overrepresented test of GBM co-culture compared to single culture. Table S2. Kyoto Encyclopedia of Genes and Genomes (KEGG) pathways that showed significant differences in overrepresented test of GBM co-culture compared to single culture. Table S3. Secretome profiling pixel intensities for individual blots.
}

\section{Abbreviations}

AMPK: Adenosine monophosphate-activated protein kinase;

ANG: Angiogenin; CCL: Chemokine ligand; CNS: Central nervous system; DE: Differential gene expression; DPP4: Dipeptidyl peptidase-4;

EGFR: Epidermal growth factor receptor; F3: Coagulation factor III; FDR: False discovery rate; FOXO: Forkhead box transcription factors; GBM: Glioblastoma; GelMA: Gelatin methacrylate; GM-CSF: Granulocyte-macrophage colonystimulating factor; GO: Gene ontology; HB-EGF: Heparin-binding epidermal growth factor-like growth factor; IGFBP: Insulin-like growth factor binding 
protein; IRF: Interferon regulatory factor; JAK: Janus kinase; KEGG: Kyoto Encyclopedia of Genes and Genomes; MAPK: Mitogen-activated protein kinase; MG: Microglia; NES: Normalized enrichment score; NLRs: Nucleotidebinding and oligomerization domain-like receptors; NF-kB: Nuclear factor kappa-beta; PDC: Patient-derived GBM cell; PTX3: Pentraxin-related protein; RIN: RNA integrity number; RNAseq: RNA sequencing; STAT: Signal transducer and activator of transcription; TIMP: Tissue inhibitor of metalloproteinase; TLRs: Toll-like receptor signaling; TNF: Tumor necrosis factor; VEGF: Vascular endothelial growth factor

\section{Acknowledgements}

We acknowledge the assistance of Dr. Alvaro Hernandez, Dr. Jenny Drnevich and Chris Wright from the Roy J. Carver Biotechnology Center at the University of Illinois Urbana-Champaign for their assistance in RNA quality testing, library preparation, RNA sequencing, and analysis. We acknowledge Haw-Wen Hsiao for generating the customized MATLAB code for mechanical testing analysis.

\section{Authors' contributions}

JEC, JL, HRG, AJS, and BACH conceived and designed the experiments. JEC, $J L$, and $S L$ performed all experiments. JNS provided critical research materials. JEC, JL, HRG, AJS, and BACH analyzed and discussed the data. JEC and BACH wrote the manuscript. JEC, JL, JNS, HRG, AJS, and BACH edited and revised the manuscript. All authors read and approved the manuscript.

\section{Funding}

Research reported in this publication was supported by the National Cancer Institute (R01CA197488, BACH), National Institute of Diabetes and Digestive and Kidney Diseases (R01DK099528, BACH), and the National Institute of Biomedical Imaging and Bioengineering (T32EB019944, JEC, JL). The content is solely the responsibility of the authors and does not necessarily represent the official views of the $\mathrm{NIH}$. The authors are also grateful for additional funding provided by the Department of Chemical \& Biomolecular Engineering (BACH) and the Carl R. Woese Institute for Genomic Biology $(\mathrm{BACH})$ at the University of Illinois at Urbana-Champaign. Development and maintenance of the GBM PDC models was supported by Mayo Clinic, the Mayo SPORE in Brain Cancer (P50 CA108961), and the Mayo Clinic Brain Tumor Patient-Derived Xenograft National Resource (R24 NS092940).

\section{Availability of data and materials}

Data and metadata associated with this manuscript are available on request to the corresponding author.

\section{Ethics approval and consent to participate}

Patient-derived xenograft models. Accrual of patient tumor samples to originally develop these models was performed with approval by the Mayo Clinic Institutional Review Board. The xenograft models being used in this project are derived from patients who are now deceased and therefore do not constitute human subjects research as per $\mathrm{NIH}$ guidelines.

Primary mouse microglia. All animal care protocols were in accordance with $\mathrm{NIH}$ Guidelines for Care and Use of Laboratory Animals and were approved by the University of Illinois Laboratory Animal Care and Use Committee and by the Mayo Clinic Institutional Animal Care and Use Committee.

\section{Consent for publication}

All authors of the manuscript have read and agreed to its content and are accountable for all aspects of the accuracy and integrity of the manuscript.

\section{Competing interests}

The authors declare that they have no competing interests.

\section{Author details}

'Department of Chemical \& Biomolecular Engineering, University of Illinois at Urbana-Champaign, Urbana, IL 61801, USA. ${ }^{2}$ Carl R. Woese Institute for Genomic Biology, University of Illinois at Urbana-Champaign, Urbana, IL 61801 , USA. ${ }^{3}$ Department of Materials Science and Engineering, University of Illinois at Urbana-Champaign, Urbana, IL 61801, USA. ${ }^{4}$ Division of Nutritional Sciences, University of Illinois at Urbana-Champaign, Urbana, IL 61801, USA. ${ }^{5}$ Current Address: Salk Institute for Biological Studies, La Jolla, CA, USA. ${ }^{6}$ Department of Chemistry, University of Illinois at Urbana-Champaign, Urbana, IL 61801, USA. ${ }^{7}$ Department of Radiation Oncology, Mayo Clinic,
Rochester, MN, USA. ${ }^{8}$ Department of Animal Sciences, University of Illinois at Urbana-Champaign, 110 Roger Adams Laboratory, 600 S. Mathews Ave, Urbana, IL 61801, USA. ${ }^{9}$ Cancer Center at Illinois, University of Illinois at Urbana-Champaign, 110 Roger Adams Laboratory, 600 S. Mathews Ave, Urbana, IL 61801, USA.

Received: 5 August 2020 Accepted: 5 November 2020

Published online: 18 November 2020

\section{References}

1. Siegel RL, Miller KD, Jemal A. Cancer statistics, 2019. CA. 2019;69:7-34.

2. Thakkar JP, Dolecek TA, Horbinski C, Ostrom QT, Lightner DD, BarnholtzSloan JS, Villano JL. Epidemiologic and molecular prognostic review of glioblastoma. Cancer Epidemiol Biomarker Prev. 2014;23:1985-96.

3. Zhang J, Stevens MF, Bradshaw TD. Temozolomide: mechanisms of action, repair and resistance. Curr Mol Pharmacol. 2012;5:102-14.

4. de Groot JF, Fuller G, Kumar AJ, Piao Y, Eterovic K, Ji Y, Conrad CA. Tumor invasion after treatment of glioblastoma with bevacizumab: radiographic and pathologic correlation in humans and mice. Neuro-Oncology. 2010;12: 233-42.

5. Anne C, Catherine G, Rogatien F, Clément T, Alice B, Laurent L, Audrey R, Tony A, Cécile H, Olivier C, Philippe M. Glioblastoma-associated stromal cells (GASCs) from histologically normal surgical margins have a myofibroblast phenotype and angiogenic properties. J Pathol. 2014;233:74-88.

6. Paolillo M, Boselli C, Schinelli S. Glioblastoma under siege: an overview of current therapeutic strategies. Brain Sci. 2018:8:15.

7. Johnson DR, O'Neill BP. Glioblastoma survival in the United States before and during the temozolomide era. Journal of Neuro-Oncology. 2012;107: 359-64

8. Jackson C, Ruzevick J, Phallen J, Belcaid Z, Lim M. Challenges in immunotherapy presented by the glioblastoma multiforme microenvironment. Clin Dev Immunol. 2011;2011:732413.

9. Stupp R, Mason WP, van den Bent MJ, Weller M, Fisher B, Taphoorn MJB, Belanger K, Brandes AA, Marosi C, Bogdahn U, et al. Radiotherapy plus concomitant and adjuvant temozolomide for glioblastoma. New Eng J Med 2005;352:987-96.

10. Mehta Al, Linninger $\mathrm{A}$, Lesniak MS, Engelhard $\mathrm{HH}$. Current status of intratumoral therapy for glioblastoma. J Neuro Oncol. 2015;125:1-7.

11. Cantrell JN, Waddle MR, Rotman M, Peterson JL, Ruiz-Garcia H, Heckman MG, Quinones-Hinojosa A, Rosenfeld SS, Brown PD, Trifiletti DM. Progress toward long-term survivors of glioblastoma. Mayo Clin Proceed. 2019:94: 1278-86.

12. Cohen MH, Johnson JR, Pazdur R. Food and drug administration drug approval summary: temozolomide plus radiation therapy for the treatment of newly diagnosed glioblastoma multiforme. Clin Cancer Res. 2005;11:6767-71.

13. Liu Y, Hao S, Yu L, Gao Z. Long-term temozolomide might be an optimal choice for patient with multifocal glioblastoma, especially with deep-seated structure involvement: a case report and literature review. World I Surg Oncol. 2015;13:142.

14. Wallner KE, Galicich JH, Krol G, Arbit E, Malkin MG. Patterns of failure following treatment for glioblastoma multiforme and anaplastic astrocytoma. Int J Rad Oncol Biol Phys. 1989:16:1405-9.

15. Delgado-López PD, Corrales-García EM. Survival in glioblastoma: a review on the impact of treatment modalities. Clin Transl Oncol. 2016;18:1062-71.

16. Choucair AK, Levin VA, Gutin PH, Davis RL, Silver P, Edwards MSB, Wilson CB. Development of multiple lesions during radiation therapy and chemotherapy in patients with gliomas. J Neurosurg. 1986;65:654-8.

17. Kirkpatrick JP, Sampson JH. Recurrent Malignant Gliomas. Seminars Rad Oncol. 2014;24:289-98.

18. Tait MJ, Petrik V, Loosemore A, Bell BA, Papadopoulos MC. Survival of patients with glioblastoma multiforme has not improved between 1993 and 2004: analysis of 625 cases. Br J Neurosurg. 2007;21:496-500.

19. Hambardzumyan D, Gutmann DH, Kettenmann H. The role of microglia and macrophages in glioma maintenance and progression. Nat Neurosci. 2016; 19:20-7.

20. Roesch S, Rapp C, Dettling S, Herold-Mende C. When immune cells turn bad-tumor-associated microglia/macrophages in glioma. Int J Mol Sci. 2018; 19:436.

21. Prionisti I, Bühler LH, Walker PR, Jolivet RB. Harnessing microglia and macrophages for the treatment of glioblastoma. Front Pharmacol. 2019;10:506. 
22. Casano AM, Peri F. Microglia: multitasking specialists of the brain. Dev Cell. 2015;32:469-77.

23. Zhang M, Hutter G, Kahn SA, Azad TD, Gholamin S, Xu CY, Liu J, Achrol AS, Richard C, Sommerkamp P, et al. Anti-CD47 treatment stimulates phagocytosis of glioblastoma by M1 and M2 polarized macrophages and promotes M1 polarized macrophages in vivo. PLOS ONE. 2016;11:e0153550.

24. Mignogna C, Signorelli F, Vismara MFM, Zeppa P, Camastra C, Barni T, Donato G, Di Vito A. A reappraisal of macrophage polarization in glioblastoma: Histopathological and immunohistochemical findings and review of the literature. Pathol Res Pract. 2016;212:491-9.

25. Noy R, Pollard Jeffrey W. Tumor-associated macrophages: from mechanisms to therapy. Immunity. 2014;41:49-61.

26. Matias D, Balça-Silva J, da Graça GC, Wanjiru CM, Macharia LW, Nascimento $\mathrm{CP}$, Roque NR, Coelho-Aguiar JM, Pereira CM, Dos Santos MF, et al. Microglia/astrocytes-glioblastoma crosstalk: crucial molecular mechanisms and microenvironmental factors. Front Cell Neurosci. 2018;12:235.

27. Graeber MB, Scheithauer BW, Kreutzberg GW. Microglia in brain tumors. Glia. 2002;40:252-9

28. Lewis-Tuffin LJ, Rodriguez F, Giannini C, Scheithauer B, Necela BM, Sarkaria $\mathrm{JN}$, Anastasiadis PZ. Misregulated E-cadherin expression associated with an aggressive brain tumor phenotype. PLOS ONE. 2010;5:e13665.

29. Sivakumar H, Strowd R, Skardal A. Exploration of dynamic elastic modulus changes on glioblastoma cell populations with aberrant EGFR expression as a potential therapeutic intervention using a tunable hyaluronic acid hydrogel platform. Gels. 2017;3(3):28.

30. Chen J-WE, Pedron S, Harley BAC. The combined influence of hydrogel stiffness and matrix-bound hyaluronic acid content on glioblastoma invasion. Macromolecular Bioscience. 2017;17:1700018.

31. Chen J-WE, Pedron S, Shyu P, Hu Y, Sarkaria JN, Harley BAC. Influence of hyaluronic acid transitions in tumor microenvironment on glioblastoma malignancy and invasive behavior. Front Mater. 2018;5:39.

32. Chen J-WE, Lumibao J, Blazek A, Gaskins HR, Harley B. Hypoxia activates enhanced invasive potential and endogenous hyaluronic acid production by glioblastoma cells. Biomater Sci. 2018;6:854-62.

33. Ngo MT, Karvelis E, Harley BAC. Multidimensional hydrogel models reveal endothelial network angiocrine signals increase glioblastoma cell number, invasion, and temozolomide resistance. Integr Biol. 2020;12:139-49.

34. Sarkaria JN, Carlson BL, Schroeder MA, Grogan P, Brown PD, Giannini C, Ballman KV, Kitange GJ, Guha A, Pandita A, James CD. Use of an orthotopic xenograft model for assessing the effect of epidermal growth factor receptor amplification on glioblastoma radiation response. Clin Cancer Res. 2006;12:2264-71

35. Sarkaria JN, Yang L, Grogan PT, Kitange GJ, Carlson BL, Schroeder MA, Galanis E, Giannini C, Wu W, Dinca EB, James CD. Identification of molecular characteristics correlated with glioblastoma sensitivity to EGFR kinase inhibition through use of an intracranial xenograft test panel. Mol Cancer Therapeutics. 2007;6:1167-74

36. Soto-Díaz K, Juda MB, Blackmore S, Walsh C, Steelman AJ. TAK1 inhibition in mouse astrocyte cultures ameliorates cytokine-induced chemokine production and neutrophil migration. J Neurochem. 2019;152:697-709.

37. Pedron S, Becka E, Harley BAC. Regulation of glioma cell phenotype in $3 D$ matrices by hyaluronic acid. Biomaterials. 2013;34:7408-17.

38. Hopperton KE, Mohammad D, Trépanier MO, Giuliano V, Bazinet RP. Markers of microglia in post-mortem brain samples from patients with Alzheimer's disease: a systematic review. Mol Psychiatry. 2018;23:177-98.

39. Robinson MD, McCarthy DJ, Smyth GK. edgeR: a Bioconductor package for differential expression analysis of digital gene expression data. Bioinformatics (Oxford, England). 2010;26:139-40.

40. Robinson MD, Oshlack A. A scaling normalization method for differential expression analysis of RNA-seq data. Genome Biol. 2010;11:R25.

41. Patro R, Duggal G, Love MI, Irizarry RA, Kingsford C. Salmon provides fast and bias-aware quantification of transcript expression. Nat Method. 2017;14: 417-9.

42. Benjamini $Y$, Hochberg $Y$. Controlling the false discovery rate: a practical and powerful approach to multiple testing. J R Stat Soc. 1995;57:289-300.

43. Law CW, Chen Y, Shi W. Smyth GK: voom: precision weights unlock linear model analysis tools for RNA-seq read counts. Genome Biol. 2014;15:R29.

44. Chen Y, Lun A, Smyth G. From reads to genes to pathways: differentia expression analysis of RNA-Seq experiments using Rsubread and the edgeR quasi-likelihood pipeline [version 2; peer review: 5 approved] F1000Research. 2016;5:1438.
45. Gentleman RC, Carey VJ, Bates DM, Bolstad B, Dettling M, Dudoit S, Ellis B, Gautier L, Ge Y, Gentry J, et al. Bioconductor: open software development for computational biology and bioinformatics. Genome Biol. 2004;5:R80.

46. Janky R, Verfaillie A, Imrichová H, Van de Sande B, Standaert L, Christiaens V, Hulselmans G, Herten K, Naval Sanchez M, Potier D, et al. iRegulon: from a gene list to a gene regulatory network using large motif and track collections. PLOS Comput Biol. 2014;10:e1003731.

47. Maere S, Heymans K, Kuiper M. BiNGO: a Cytoscape plugin to assess overrepresentation of gene ontology categories in biological networks. Bioinformatics. 2005:21:3448-9.

48. Chen J-W, Blazek A, Lumibao J, Gaskins HR, Harley BAC. Hypoxia activates enhanced invasive potential and endogenous hyaluronic acid production by glioblastoma cells. Biomater Sci. 2018;6:854-62.

49. Chen J-WE, Pedron S, Shyu P, Hu Y, Sarkaria JN, Harley BAC. Influence of hyaluronic acid transitions in tumor microenvironment on glioblastoma malignancy and invasive behavior. Front Mater. 2018;5.

50. Chen J-W, Pedron S, Harley BAC. The combined influence of hydrogel stiffness and matrix-bound hyaluronic acid content on glioblastoma invasion. Macromol Biosci. 2017;17:1700018.

51. Pedron S, Becka E, Harley BA. Spatially Gradated Hydrogel Platform as a 3D Engineered Tumor Microenvironment. Adv Mater. 2015;27:1567-72.

52. Pedron S, Wolter GL, Chen J-WE, Laken SE, Sarkaria JN, Harley BAC. Hyaluronic acid-functionalized gelatin hydrogels reveal extracellular matrix signals temper the efficacy of erlotinib against patient-derived glioblastoma specimens. Biomaterials. 2019;219:119371.

53. Pedron S, Harley BAC. The impact of the biophysical features of a 3D gelatin microenvironment on glioblastoma malignancy. J Biomed Mater Res Pt A. 2013;101:3405-15.

54. Richbourg N, Wancura M, Gilchrist AE, Toubbeh S, Harley BAC, CosgriffHernandez E, Peppas NA. Hydrogel synthesis conditions control swelling and predict stiffness and solute diffusivity. in revision; 2020.

55. Gilchrist AE, Lee $\mathrm{S}$, Hu Y, Harley BAC. Soluble signals and remodeling in a synthetic gelatin-based hematopoietic stem cell niche. Adv Healthc Mater. 2019;8:1900751.

56. Barnhouse V, Petrikas N, Crosby C, Zoldan J, BAC H. Perivascular secretome influences hematopoietic stem cell maintenance in a gelatin hydrogel. Ann Biomed Eng. 2020

57. Ngo MT, Karvelis E, Harley BAC. Multidimensional hydrogel models reveal endothelial network angiocrine signals increase glioblastoma cell number, invasion, and temozolomide resistance. Integr Biol (Camb). 2020;12:139-49.

58. Zambuto SG, Serrano JF, Vilbert AC, Lu Y, Harley BAC, Pedron S. Response of neuroglia to hypoxia-induced oxidative stress using enzymatically crosslinked hydrogels. MRS Communications. 2020;10:83-90.

59. Pogoda K, Chin L, Georges PC, Byfield FJ, Bucki R, Kim R, Weaver M, Wells RG, Marcinkiewicz C, Janmey PA. Compression stiffening of brain and its effect on mechanosensing by glioma cells. New J Phys. 2014;16:075002.

60. Budday S, Nay R, de Rooij R, Steinmann P, Wyrobek T, Ovaert TC, Kuhl E. Mechanical properties of gray and white matter brain tissue by indentation. J Mechanic Behavior of Biomedical Materials. 2015;46:318-30.

61. Giese A, Loo MA, Tran N, Haskett D, Coons SW, Berens ME. Dichotomy of astrocytoma migration and proliferation. Int J Cancer. 1996;67:275-82.

62. Lemstra AW, JCM G i't W, JJM H, van Haastert ES, AJM R, Eikelenboom P, van Gool WA. Microglia activation in sepsis: a case-control study. J Neuroinflamm. 2007:4:4.

63. Wang Z, Gerstein M, Snyder M. RNA-Seq: a revolutionary tool for transcriptomics. Nat Rev Gene. 2009;10:57-63.

64. Oliveira Al, Anjo SI, Vieira de Castro J, Serra SC, Salgado AJ, Manadas B, Costa BM. Crosstalk between glial and glioblastoma cells triggers the "go-or-grow" phenotype of tumor cells. Cell Commun Signal. 2017; 15:37.

65. Hatzikirou H, Basanta D, Simon M, Schaller K, Deutsch A. 'Go or grow': the key to the emergence of invasion in tumour progression? Math Med Biol. 2012;29:49-65.

66. Fukata M, Vamadevan AS, Abreu MT. Toll-like receptors (TLRs) and Nod-like receptors (NLRs) in inflammatory disorders. Seminar Immunol. 2009;21:242-53.

67. Kim YK, Shin JS, Nahm MH. NOD-like receptors in infection, immunity, and diseases. Yonsei Med J. 2016:57:5-14.

68. Tarassishin L, Casper D, Lee SC. Aberrant expression of interleukin-1 $\beta$ and inflammasome activation in human malignant gliomas. PLOS ONE. 2014;9: e103432. 
69. Ryuto M, Ono M, Izumi H, Yoshida S, Weich HA, Kohno K, Kuwano M. Induction of vascular endothelial growth factor by tumor necrosis factor a in human glioma cells: possible roles of SP-1. J Biol Chem. 1996;271:28220-8.

70. Hayden MS, Ghosh S. Regulation of NF-kB by TNF family cytokines. Seminar Immunol. 2014;26:253-66.

71. Chandrika G, Natesh K, Ranade D, Chugh A, Shastry P. Suppression of the invasive potential of Glioblastoma cells by mTOR inhibitors involves modulation of NFKB and PKC-a signaling. Sci Rep. 2016;6:22455.

72. Town T, Nikolic $V$, Tan J. The microglial "activation" continuum: from innate to adaptive responses. J Neuroinflam. 2005;2:24.

73. Moynagh PN. The NF-kB pathway. J Cell Sci. 2005;118:4589-92.

74. Wang F, Zhang P, Yang L, Yu X, Ye X, Yang J, Qian C, Zhang X, Cui YH, Bian $X W$. Activation of toll-like receptor 2 promotes invasion by upregulating MMPs in glioma stem cells. Am J Transl Res. 2015;7:607-15.

75. Flamant F, Cheng S-Y, Hollenberg AN, Moeller LC, Samarut J, Wondisford FE, Yen PM, Refetoff S. Thyroid hormone signaling pathways: time for a more precise nomenclature. Endocrinology. 2017;158:2052-7.

76. Davis FB, Tang HY, Shih A, Keating T, Lansing L, Hercbergs A, Fenstermaker RA, Mousa A, Mousa SA, Davis PJ, Lin HY. Acting via a cell surface receptor, thyroid hormone is a growth factor for glioma cells. Cancer Res. 2006;66: 7270-5.

77. Lin HY, Glinsky GV, Mousa SA, Davis PJ. Thyroid hormone and anti-apoptosis in tumor cells. Oncotarget. 2015;6:14735-43.

78. Page BDG, Fletcher S, Yue P, Li Z, Zhang X, Sharmeen S, Datti A, Wrana JL, Trudel S, Schimmer AD, et al. Identification of a non-phosphorylated, cell permeable, small molecule ligand for the Stat3 SH2 domain. Bioorganic Med Chem Letters. 2011;21:5605-9.

79. Zhang J, Xu S, Xu J, Li Y, Zhang J, Zhang J, Lu X. miR-767-5p inhibits glioma proliferation and metastasis by targeting SUZ12. Oncol Rep. 2019;42:55-66.

80. Martín-Pérez D, Sánchez E, Maestre L, Suela J, Vargiu P, Di Lisio L, Martínez $\mathrm{N}$, Alves J, Piris MA, Sánchez-Beato M. Deregulated expression of the polycomb-group protein SUZ12 target genes characterizes mantle cell lymphoma. Am J Pathol. 2010;177:930-42.

81. Kamal MM, Sathyan P, Singh SK, Zinn PO, Marisetty AL, Liang S, Gumin J, ElMesallamy HO, Suki D, Colman H, et al. REST regulates oncogenic properties of glioblastoma stem cells. Stem Cells. 2012;30:405-14.

82. Filatova A, Acker T, Garvalov BK. The cancer stem cell niche(s): The crosstalk between glioma stem cells and their microenvironment. Biochimica et Biophysica Acta (BBA) - General Subjects. 2013;1830:2496-508.

83. Sakariassen $P \varnothing$, Immervoll $H$, Chekenya M. Cancer stem cells as mediators of treatment resistance in brain tumors: status and controversies. Neoplasia (New York, NY). 2007;9:882-92.

84. Mori T, Anazawa Y, liizumi M, Fukuda S, Nakamura Y, Arakawa H. Identification of the interferon regulatory factor 5 gene (IRF-5) as a direct target for p53. Oncogene. 2002;21:2914-8.

85. Bi X, Hameed M, Mirani N, Pimenta EM, Anari J, Barnes BJ. Loss of interferon regulatory factor 5 (IRF5) expression in human ductal carcinoma correlates with disease stage and contributes to metastasis. Breast Cancer Res. 2011;13:R111.

86. Ni D, Ma X, Li HZ, Gao Y, Li XT, Zhang Y, Ai Q, Zhang P, Song EL, Huang QB, et al. Downregulation of FOXO3a promotes tumor metastasis and is associated with metastasis-free survival of patients with clear cell renal cel carcinoma. Clin Cancer Res. 2014;20:1779-90.

87. Farhan M, Wang H, Gaur U, Little PJ, Xu J, Zheng W. FOXO signaling pathways as therapeutic targets in cancer. Int J Biol Sci. 2017;13:815-27.

88. Qian Z, Ren L, Wu D, Yang X, Zhou Z, Nie Q, Jiang G, Xue S, Weng W, Qiu Y, Lin Y. Overexpression of FoxO3a is associated with glioblastoma progression and predicts poor patient prognosis. Int J Cancer. 2017;140: 2792-804.

89. Chang AL, Miska J, Wainwright DA, Dey M, Rivetta CV, Yu D, Kanojia D, Pituch KC, Qiao J, Pytel P, et al. CCL2 produced by the glioma microenvironment is essential for the recruitment of regulatory $T$ cells and myeloid-derived suppressor cells. Cancer Res. 2016;76:5671-82.

90. Vakilian A, Khorramdelazad H, Heidari P, Sheikh Rezaei Z, Hassanshahi G. CCL2/CCR2 signaling pathway in glioblastoma multiforme. Neurochem Int. 2017;103:1-7.

91. Guan E, Wang J, Norcross MA. Identification of human macrophage inflammatory proteins $1 a$ and $1 \beta$ as a native secreted heterodimer. J Biol Chem. 2001;276:12404-9.

92. Gill ZP, Perks CM, Newcomb PV, Holly JM. Insulin-like growth factor-binding protein (IGFBP-3) predisposes breast cancer cells to programmed cell death in a non-IGF-dependent manner. J Biol Chem. 1997;272:25602-7.
93. Watanabe K, Uemura K, Asada M, Maesako M, Akiyama H, Shimohama S, Takahashi R, Kinoshita A. The participation of insulin-like growth factorbinding protein 3 released by astrocytes in the pathology of Alzheimer's disease. Mol Brain. 2015;8:82.

94. Kielczewski JL, Hu P, Shaw LC, Li Calzi S, Mames RN, Gardiner TA, McFarland E, Chan-Ling T, Grant MB. Novel protective properties of IGFBP-3 result in enhanced pericyte ensheathment, reduced microglial activation, increased microglial apoptosis, and neuronal protection after ischemic retinal injury. Am J Pathol. 2011;178:1517-28.

95. Matteucci E, Giampietro O. Dipeptidyl peptidase-4 (CD26): knowing the function before inhibiting the enzyme. Curr Med Chem. 2009;16: 2943-51.

96. Stremenova J, Krepela E, Mares V, Trim J, Dbaly V, Marek J, Vanickova Z, Lisa $V$, Yea C, Sedo A. Expression and enzymatic activity of dipeptidyl peptidaseIV in human astrocytic tumours are associated with tumour grade. Int J Oncol. 2007;31:785-92.

97. Pethiyagoda CL, Welch DR, Fleming TP. Dipeptidyl peptidase IV (DPPIV) inhibits cellular invasion of melanoma cells. Clin Exp Metastasis. 2000;18: 391-400.

98. F. Riordan J. [16] - Angiogenin. In: Methods in Enzymology. Volume 341 Edited by Nicholson AW: Academic Press; 2001. p. 263-73.

99. Sheng J, Xu Z. Three decades of research on angiogenin: a review and perspective. Acta Biochimica et Biophysica Sinica. 2015;48:399-410.

100. DeCoster MA, Schabelman E, Tombran-Tink J, Bazan NG. Neuroprotection by pigment epithelial-derived factor against glutamate toxicity in developing primary hippocampal neurons. J Neurosci Res. 1999:56:604-10.

101. Doll JA, Stellmach VM, Bouck NP, Bergh AR, Lee C, Abramson LP, Cornwell ML, Pins MR, Borensztajn J, Crawford SE. Pigment epithelium-derived factor regulates the vasculature and mass of the prostate and pancreas. Nat Med. 2003;9:774-80.

102. Filleur S, Nelius T, de Riese W, Kennedy RC. Characterization of PEDF: a multi-functional serpin family protein. J Cell Biochem. 2009;106: 769-75.

103. Guan M, Pang C-P, Yam H-F, Cheung K-F, Liu W-W, Lu Y. Inhibition of glioma invasion by overexpression of pigment epithelium-derived factor. Cancer Gene Ther. 2004;11:325-32.

104. Shinozaki Y, Shibata K, Yoshida K, Shigetomi E, Gachet C, Ikenaka K, Tanaka KF, Koizumi S. Transformation of astrocytes to a neuroprotective phenotype by microglia via P2Y1 receptor downregulation. Cell Rep. 2017;19:1151-64

105. Gilchrist AE, Harley BAC. Connecting secretome to hematopoietic stem cell phenotype shifts in an engineered bone marrow niche. Integr Biol (Camb). 2020;12(7):175-87.

106. Abels ER, Maas SLN, Nieland L, Wei Z, Cheah PS, Tai E, Kolsteeg CJ, Dusoswa SA, Ting DT, Hickman S, et al. Glioblastoma-Associated Microglia Reprogramming Is Mediated by Functional Transfer of Extracellular miR-21. Cell Rep. 2019;28:3105-19 e3107.

107. Wei J, Gabrusiewicz K, Heimberger A. The controversial role of microglia in malignant gliomas. Clin Dev Immunol. 2013;2013:12.

108. Charles NA, Holland EC, Gilbertson R, Glass R, Kettenmann H. The brain tumor microenvironment. Glia. 2011;59:1169-80.

109. Binda E, Visioli A, Reynolds B, Vescovi AL. Heterogeneity of cancer-initiating cells within glioblastoma. Front Biosci (Schol Ed). 2012;4:1235-48.

110. Reynolds BA, Vescovi AL. Brain cancer stem cells: think twice before going flat. Cell Stem Cell. 2009;5:466-7.

111. Lathia JD, Mack SC, Mulkearns-Hubert EE, Valentim CL, Rich JN. Cancer stem cells in glioblastoma. Genes Dev. 2015;29:1203-17.

112. Uemae Y, Ishikawa E, Osuka S, Matsuda M, Sakamoto N, Takano S, Nakai K, Yamamoto T, Matsumura A. CXCL12 secreted from glioma stem cells regulates their proliferation. J Neurooncol. 2014;117:43-51.

113. Sun L, Hui AM, Su Q, Vortmeyer A, Kotliarov Y, Pastorino S, Passaniti A, Menon J, Walling J, Bailey R, et al. Neuronal and glioma-derived stem cell factor induces angiogenesis within the brain. Cancer Cell. 2006;9: 287-300.

114. Baysan M, Woolard K, Bozdag S, Riddick G, Kotliarova S, Cam MC, Belova Gl, Ahn S, Zhang W, Song H, et al. Micro-environment causes reversible changes in DNA methylation and mRNA expression profiles in patientderived glioma stem cells. PLoS One. 2014;9:e94045.

115. Binda E, Reynolds BA, Vescovi AL. Glioma stem cells: turpis omen in nomen? (The evil in the name?). J Intern Med. 2014;276:25-40. 
116. Lemke D, Weiler M, Blaes J, Wiestler B, Jestaedt L, Klein AC, Low S, Eisele G, Radlwimmer B, Capper D, et al. Primary glioblastoma cultures: can profiling of stem cell markers predict radiotherapy sensitivity? J Neurochem. 2014; 131:251-64.

117. Hambardzumyan D, Cheng Y-K, Haeno H, Holland EC, Michor F. The probable cell of origin of NF1- and PDGF-driven glioblastomas. PLOS ONE. 2011;6:e24454.

118. Wiranowska MR, M. V.: Extracellular matrix microenvironment in glioma progression. In Glioma - Exploring Its Biology and Practical Relevance. Edited by Ghosh A: InTech; 2011: 257-284.

\section{Publisher's Note}

Springer Nature remains neutral with regard to jurisdictional claims in published maps and institutional affiliations.

Ready to submit your research? Choose BMC and benefit from:

- fast, convenient online submission

- thorough peer review by experienced researchers in your field

- rapid publication on acceptance

- support for research data, including large and complex data types

- gold Open Access which fosters wider collaboration and increased citations

- maximum visibility for your research: over $100 \mathrm{M}$ website views per year

At BMC, research is always in progress.

Learn more biomedcentral.com/submissions 